\title{
INCREASED PLASMA TOTAL CHOLESTEROL AND HIGH DENSITY LIPOPROTEIN LEVELS PRODUCED BY THE CRUDE EXTRACT FROM THE LEAVES OF VISCUM ALBUM (MISTLETOE).
}

\author{
E. E. BEN, A. E. ENO ${ }^{1}$, O. E. OFEM ${ }^{1}$, U. AIDEM ${ }^{1}$ and E. H. ITAM ${ }^{2}$ \\ Department of Physiology, University of Uyo, Uyo, Nigeria, adoofpraise@yahoo.com +234 8035403973 \\ Departments of Physiology ${ }^{l}$ and Biochemistry ${ }^{2}$, University of Calabar, Calabar, Nigeria \\ E-mail: nkineno2000@yahoo.co.uk Tel: +234805566 4612,ofemo2003@yahoo.com
}

\begin{abstract}
Summary: The effect of an aqueous extract prepared from the leaves of Viscum album (Mistletoe) on plasma cholesterol and albumin levels in male Wistar rats was studied. Lethality studies revealed that the extract had an $\mathrm{LD}_{50}$ value of $417.0 \mathrm{mg} / \mathrm{kg}$ mice, intraperitoneally. The rats were randomly divided into seven (7) groups of 5 rats per group with one animal per metabolic cage. Group one served as the control (C1), groups two to six were treated with extract $(200 \mathrm{mg} / \mathrm{kg}$ body weight orally and daily) for a maximum of ten (10) weeks, whereas, group seven (C2) received no extract treatment but was fed on normal rat chow. All the rats had free access to rat food and drinking water. The first group (C1) was sacrificed a fortnight after the commencement of the experiment, while group seven (C2) was sacrificed at the end $\left(10^{\text {th }}\right.$ week) of the experiment. The extract-treated groups were sacrificed respectively in the order 2,4,6,8 and 10 week of extract administration. Whole blood was collected from these groups for analysis. Results showed significant increases $(\mathrm{P}<0.01)$ in the level of total cholesterol (TC) from $1.92 \pm 0.11 \mathrm{mmol} / \mathrm{L}$ to $2.59 \pm 0.02 \mathrm{mmol} / \mathrm{L}$ (about $35 \%$ increase) and high density lipoproteins (HDL) from $0.95 \pm 0.02 \mathrm{mmol} / \mathrm{L}$ to $1.50 \pm 0.08 \mathrm{mmol} / \mathrm{L}$ (about $58.50 \%$ increase) at week 10. The LDL levels, the total protein and albumin levels did not show any significant change from the control values. From the results, it is suggested that the crude aqueous extract from mistletoe leaf may be relatively safe for therapeutic use as it neither predisposes to cardiovascular risk nor adversely affects protein metabolism following prolonged period of administration.
\end{abstract}

Key Words: Lipid profile, plasma protein, mistletoe, extract, safe.

\section{Introduction}

Viscum album (Mistletoe) is a semiparasitic plant with apparent broad spectrum of therapeutic action (Hutt et al, 2000, Eno et al., 2004). Following its wide use and abundance in Britain, it is commonly known as "European mistletoe". However, there are other species spread in various places which may function either the same or differently from the European mistletoe. It is reported that mistletoe is used generally as immunomodulatory and anti-cancer agents (Bussing, 1990; Hajto, 1999).

Other ailments in which it is used includes the treatment of type-1 diabetes mellitus, management of serum cholesterol, arthritis, hysteria, asthma, hypertension and other symptoms connected with raised blood pressure (Bussing, 1999). Some human studies reported by Newall (1990) had it that mistletoe treatment improves quality of life and survival rate for people with cancer. In Nigeria, dried mistletoe leaves are being sold in sachets to be taken as tea in order to provide preventive therapy (Eno et al., 2004).

Hypercholesterolaemia, hypertension and atherosclerosis have been identified as independent "risk factors" for the development of premature cardiovascular diseases (CVD) (Chatterjea and Shride, 2002). According to Conderce, (1999) and Igwe et al., (2003), high level of LDL-cholesterol and low level of HDL-cholesterol have been strongly associated with the risk of coronary heart disease (CHD). Epidermiological data continue to support the inverse correlation between HDL-cholesterol level and clinically significant atherosclerotic disease (Jones, 1998; Zheng et al., 1999). Abnormally low level of HDL-cholesterol is associated with increased possibility of atherosclerosis, probably because of disrupted reverse cholesterol transport (Conderce, 1999; Chatterjea and Shride, 2002).

In this present studies, effort to assess the effect of the leaf extract on the lipid profile and plasma proteins in a non-diseased condition 
was made. Our aim was to investigate if patients undergoing mistletoe therapy were predisposed to other diseases (e.g. CDC) or were capable of suffering from any adverse effect (s) of such treatment.

\section{Materials and Methods \\ Preparation of Crude Aqueous Extract:}

Fresh leaves of Viscum album from the host plant (citrus) were collected. The leaves were first washed free of sand and debris. Wash water was blotted off and the leaves ground to paste. A quantity of the ground sample (50g) was weighed and soxhlet extracted with $150 \mathrm{ml}$ distilled water at $100^{\circ} \mathrm{C}$ for $8-10 \mathrm{hr}$. Where larger ground samples were used, extraction was done under reflux with an appropriate volume of distilled water. The extract was slowly evaporated to dryness in vacuo at $40^{\circ} \mathrm{C}$ using a rotary evaporator. A total yield of $31 \%$ was obtained. Weighed samples of the extract were then used to prepare the stock solution.

Acute Toxicity Study

Seventy male albino Wistar mice weighing $18-20 \mathrm{~g}$ were randomly assigned to seven (7) cages of 10 animals per cage. Each group respectively received the following doses; 50, 100, 200, 400, 800, 1600mg/kg body weight of the extract intraperitoneally (i.p). The maximum volume injected was $0.2 \mathrm{ml}$ and the control group received $0.2 \mathrm{ml}$ of normal saline i.p. The mortality from each cage was monitored for 24hours following extract administration. Percentage mortalities were converted to probits (a probability unit) plotted against the $\log _{10}$ of the dose of the extract (Eno et al., 2001). From the curve, the $\mathrm{LD}_{50}$ value of the extract was extrapolated.

\section{Experimental design}

Thirty-five male albino Wistar rats were randomly assigned into seven groups of 5 rats per group. In all the groups, each rat was randomly assigned to a metabolic cage. Group one (untreated group) served as the control, groups 2-6 were treated with the extract and group seven also was untreated (control-2) kept throughout the duration of the experiment. After 2 weeks acclimatization, the extract was administered orally at a dose of $200 \mathrm{mg} / \mathrm{kg}$ body weight per day for 10 weeks maximum. The animal's body weights were taken weekly to maintain the working dose. The treated groups were sacrificed after 2,4,6,8 and 10 weeks of extract administration respectively. Group one animals were sacrificed in the first fortnight while group seven was in the last day of the experiment $\left(10^{\text {th }}\right.$ week $)$.

\section{Samples collection and preparation}

Whole blood sample was collected from each group fortnightly. After sedating the animals with chloroform, they were dissected to expose the heart. Using syringes and needles, the blood was collected from the heart and stored in the EDTA sample bottles. The blood samples were centrifuged at $1000 \mathrm{rpm}$ for 10 minutes. The separated plasma was then collected and stored in universal sample bottles in the freezer for use in the various analyses.

\section{Estimation of Plasma cholesterol}

Estimation of the total cholesterol (TC) and high density lipoprotein (HDL) was by spectrophotometric technique using autoanalysis reagent kits (Tietz, 1994). The low density lipoprotein (LDL) was obtained mathematically using the formula (Friedewalla et al., 1972)

LDL $(\mathrm{mmol} / \mathrm{L})$ - Total cholesterol $(\mathrm{mmol} / \mathrm{L})$ HDL (mmol/L) - TG/22 (mmol/L)

\section{Estimation of Plasma proteins}

In the estimation of plasma total proteins and albumen, Biuret method was used with auto-analysis spectrophotometer.

\section{Results}

Acute Toxicity

Lethality studies showed that the crude extract from the leaves of Viscum album (mistletoe) had an $\mathrm{LD}_{50}$ value of about $417 \mathrm{mg} / \mathrm{kg}$. mice, intraperitoneally. (Fig.1)

\section{Plasma Lipids Profile}

The results of the analysis of total cholesterol (TC) showed that TC increased from the mean control values of $1.29 \pm$ $0.1 \mathrm{mmol} / \mathrm{L}$ to about $2.59 \pm 0.02 \mathrm{mmol} / \mathrm{L}$. This increase represented about $35 \%$ produced by the extract and was significant at $\mathrm{P}<0.001$. However, the result also showed that about $13 \%$ of the increase in TC could be attributed to age by comparing the first and second control groups, suggesting that the actual effect of the extract was about $22 \%$ increase in TC. Fig. 2

The HDL-cholesterol results also showed significant increase from $0.95 \pm 0.05 \mathrm{mmol} / \mathrm{L}$ mean control value to about $1.50 \pm$ $0.08 \mathrm{mmol} / \mathrm{L}$ following the administration of the crude extract. Thus, a slight decrease of about $6 \%$ was observed in the LDL-cholesterol level but this was not significant. Fig. 2 


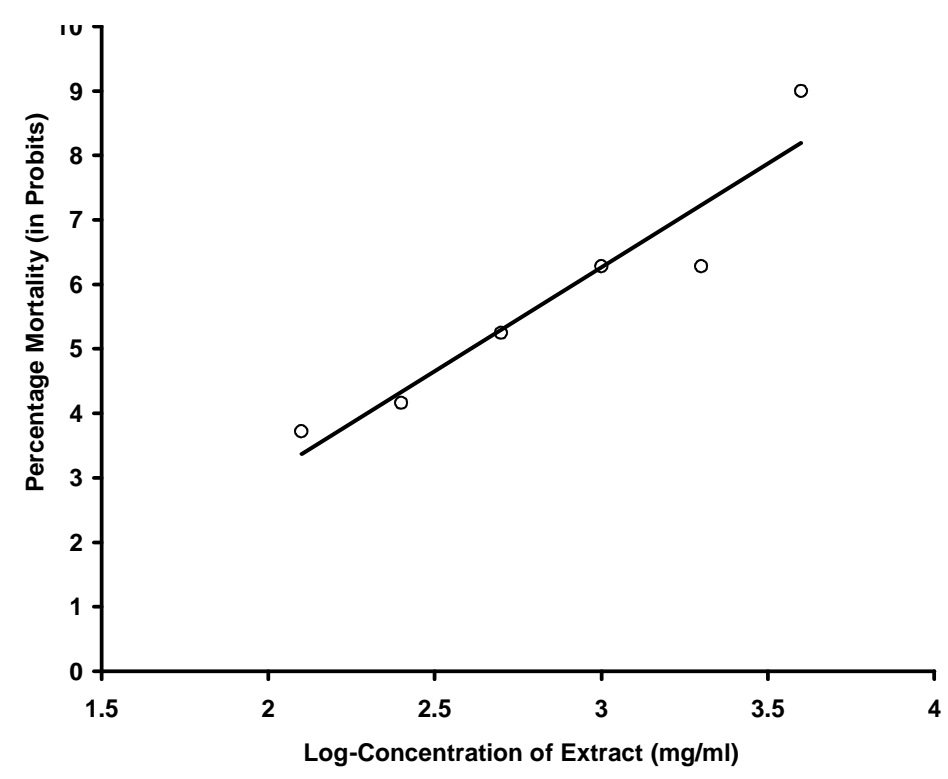

Fig. 1 Lethality studies showing the effects of administering graded doses $(50-60 \mathrm{mg} / \mathrm{kg}$ i.p. mice) of the mistletoe leaf extract against the percentage mortalities (converted to probits).

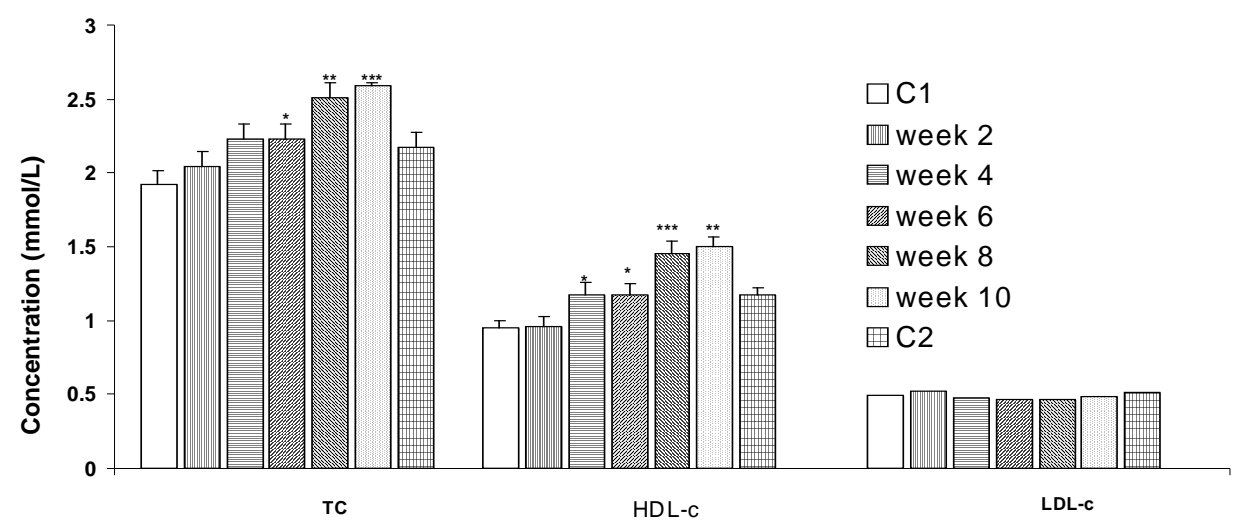

Fig. 2: Effect of crude aqueous extract of V. album on some plasma lipids in rats. Values are mean $\pm S E M, *=P<0.05, * *=P<0.01, * * *=P<0.001$

A correlation analysis (Scatter plot) showed that there was a positive correlation between total cholesterol and HDL-cholesterol $(\mathrm{r}=0.67, \mathrm{P}<0.01, \mathrm{n}=35)$. Similarly, a positive correlation was obtained between TC and LDL-cholesterol $(\mathrm{r}=0.49, \mathrm{P}<0.01, \mathrm{n}=35)$. Based on the correlation coefficient, the correlation appears to be stronger for HDL than LDL. The HDL:LDL ratio showed that the blood concentration of HDL was about 3 times higher than LDL (3:1).

\section{Plasma Proteins}

The mean total protein concentration in plasma was $4.96 \pm 0.33 \mathrm{mg} / \mathrm{dL}$. This value rose to about $5.71 \pm 0.12 \mathrm{mg} / \mathrm{dL}$ following extract administration within the experimental period (10weeks). This change was however not significant, fig. 3a. The result also showed a mean control value of about $3.85 \pm 0.14 \mathrm{mg} / \mathrm{dL}$ for plasma albumin. After extract administration, a mean albumin concentration of $4.17 \pm 0.06 \mathrm{mg} / \mathrm{dL}$ was obtained. This represents about $8 \%$ increase and was also not significant. Fig. $3 b$ 


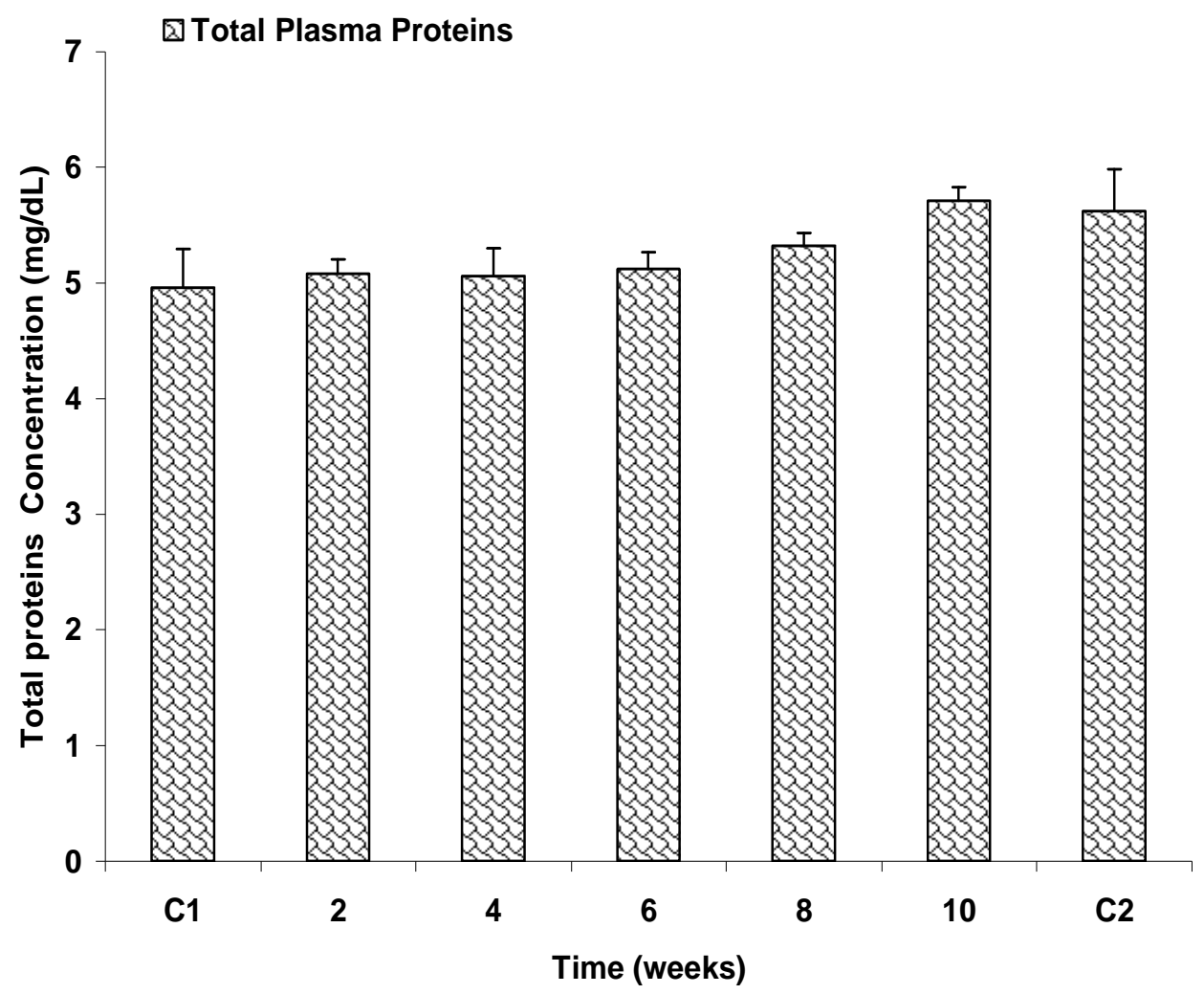

Fig. 3a Effect of crude aqueous extract of $V$. album on total plasma protein concentration in rats. Values are mean \pm SEM.

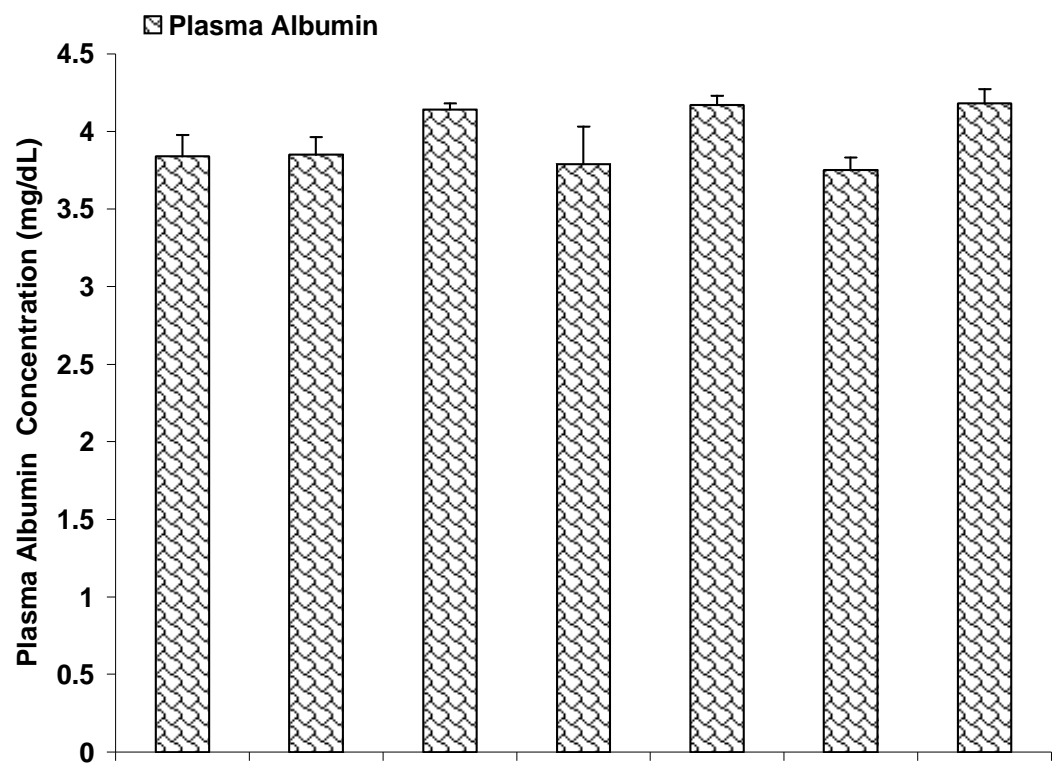

Fig. $3 b$ Effect of crude aqueous extract of $V$. album on plasma albumin concentration in rats. Values are mean \pm SEM. 


\section{Discussion}

The effect of $V$. album (mistletoe) leaf extract on a number of the formed elements (erythrocytes, leucocytes, thrombocytes) of blood is heavily documented (Imoru, 2005). Little literature is available on its effects on the contents of the fluid portion (plasma) of this tissue. The present study was therefore aimed at evaluating the effects of this extract on the lipid and protein content of plasma, since both parameters contribute tremendously to the physical and physiological characteristics of blood plasma.

The acute toxicity testing showed the $\mathrm{LD}_{50}$ value of aqueous crude extract from mistletoe leaves to be very high. This result is consistent with that reported by Ohiri (2003) which suggested that the extract had a high safety margin and may not contain any cardio- or neuro- toxic agents. This probably explains why there is a widespread use of this extract for treatment of diseases and for preventive purposes without adverse effects reported.

With respect to the lipid profile, our results suggested a time-dependent increase in the plasma total cholesterol (TC) level. This result is consistent with previous report that the TC increases with age (Chatterjea and Shinde, 2002). However, this increase in TC could be mainly due to the effect of the extract and not due to age, since the TC was also increased as early as the first fortnight of extract administration.

A significant increase in plasma level of high density lipoproteins (HDL) was also observed. According to Eder and Gidez (1982), this increase in HDL can solely be responsible for the observed increase in TC since the extract might be affecting the HDL metabolism in the liver.

The result also showed a slight decrease in low density lipoprotein (LDL) levels. This observed decrease was however not significant in all the treated groups. The extract may be having little effects on LDL metabolism. Nevertheless, according to Chartterjea and Shinde (2002), the slight decrease may be due to some influence of the extract on either receptor-dependent or receptor independent pathways of LDL catabolism in the tissues.

Following the observation that the extract increased TC and HDL but failed to influence the LDL level, it was deemed necessary to investigate which of them (HDL or LDL) relates to the TC. Scatter plots constructed revealed a positive correlation between the TC and HDL and also between TC and LDL. However, the plots also revealed that the relationship between TC and HDL was more marked or stronger than that with LDL.
Moreover, the HDL to LDL relationship was shown to be negative. This probably suggests that as the HDL increases, the LDL decreases. Therefore, it may be suggested that the observed increase in TC was largely due to increase in HDL. Also, the analysis of HDL/LDL ratio which showed that the HDL was much higher than that of LDL is in agreement with this view. The report that the HDL/LDL ratio is the actual factor responsible for the development of atherosclerotic fatty streak lesion (Stein and Berg, 1999) is also very consistent with this contention. By implication, it appears obvious that even though the plasma HDL level may be higher than that of LDL, this situation may not necessarily lead to a cardiovascular disease (CVD) risk. Therefore, the crude mistletoe leaf extract produced high plasma total cholesterol which was effectively distributed between HDL and LDL, with a greater portion to the HDL side. The extract could lead to hyperlipidaemia but not necessarily an atherogenic cardiovascular disease risk. This view is borne out of the observation that the "bad" cholesterol (LDL) was at much lower level in the plasma than the "good" cholesterol (HDL), following extract administration.

The observation that the extract spared both the plasma triglyceride (TG) and the very low density lipoprotein (VLDL) may point to its lack of any adverse effect on normal liver functions. That the liver cells were not affected (or destroyed) is further evidenced by the steady levels of the plasma total proteins and albumin, despite prolonged administration of the crude extract. Both plasma protein and albumin are preponderate in determining the oncotic pressure (Robert and Mathew, 2001), and this pressure is the key factor restricting fluid loss from capillaries. Therefore, based on the lack of effect on the plasma proteins and albumin, it may be suggested that the plasma viscosity and the volume load of the circulatory system was not affected by the subchronic administration of this crude extract. Thus, the extract may not have affected the health status of the liver adversely, nor alter significantly the fluid volume of the body fluid compartments.

In conclusion, the crude extract from the leaves of Viscum album may not have posed any cardiovascular risk since it only increased the "good" cholesterol (HDL) level leaving the level of the "bad" cholesterol (LDL) unaffected. Also, the failure of the extract to alter the plasma levels of TG and VLDL probably suggests the normal functioning of the liver despite prolonged extract administration. That the osmotic oncotic 
pressure, (which control plasma viscosity and the volume load of the circulatory system) was also not altered by the extract, is indicated by the lack of significant changes in plasma proteins and albumin. The high $\mathrm{LD}_{50}$ value obtained from this study suggests that the extract has a wide safety margin.

\section{Acknowledgement}

The authors are very grateful to Dr. E. U. Eyong and Dr. Eteng, M. U of the Department of Biochemistry, University of Calabar for a very stimulating discussion and to the management of the University of Uyo, Akwa Ibom State, for grant given to the first author.

\section{References}

Antoine, Al-Achi (2005) Mistletoe (Viscum album L.) Us Pharm. Vol 30 (1) 12-18.

Bussing, A and Schietzel, M (1999). Apoptosis inducing properties of Viscum Album L. extracts from different host trees, correlates with their content of toxic mistletoe lectins. Anticancer Res. 19:2328.

Chatterjea, M. N. and Shinde, Rana (2002). Textbook of Medical Biochemistry (5th ed.) Jaypee Brothers Medical Publishers, India Pp. $601-613$.

Conderc, R. and Machi, M. (1999). Lipoprotein (a): risk factor for atherosclerotic vascular disease important to latie into account in practice. Ann-BiolClin. 57: 157-167.

Eder, H. A. and Gidez, L. L. (1982). The clinical significance of the plasma high density lipoproteins. Med. Clin. North. Am. 66:431-434

Eno, A. E. Ibokette, U. E. Ofem, O. E.., Umoh, F. B., Nkanu, E., Azah, N. and Ibu, J. O. (2004). The effect of a Nigerian species viscum album (Mistletoe) leaf extract on the blood pressure of normotensive and DOCA-induced hypertension rats. Nig. J. Physiol. Sc. 19: 33-40.

Eno, A. E., Konya, R. S., Ibu, J. O. (2001). Changes in blood pressure in the rate induced by the venom extract from a sea anemone - Burodosoma Carvernata, Afr. J. Med. Sci. 30:75-79.
Eteng, M. U., Ebong, P. E., Ettarh, R. R., Oku, E. D. and Umoh, I. B. (2000). Theobromine administration inhibits platelet aggregation and elevates serum HDL cholesterol in hyperlipidaemic rats. Global. J. Pure Appl. Sci. 6:89-93.

Hutt, N., Kopferschmitt-kubler, M., Cabalion, J., Purohit, A, Alt, M., Pauli, G. (2001). Anaphylactic reactions after therapeutic injection of mistletoe (Viscum album L.). Allergal Immunopathol. (Med.). 29:201203.

Imoru, J., Unoh, F. B., Nkanu, E. E., Ofem, O. E. and Ibu, J. O. (2005). Haemopoietic agent(s) in the crude extract from the leaves of Viscum album (Mistletoe). Nig. J. Health Biomed. Sci. 4:139-145.

Jones P. H. (1998) .Clinical diagnosis of lipid disorders Clin. cornerstone 1 (1): 15-30.

Newall, C. A. (1996). Herbal medicines, a guide for health care professionals. London the pharmaceutical press 193-196.

Ohiri, F. C, Esimone, C. O., Nwafor, S. V., Okoli C. O. and Ndu O. O. (2003). Hypoglycemic properties of viscum album (mistletoe) in Alloxan -induced Diabetic Animals. Pharmaceutical Biology 41(3)184-187.

Pamela, C., C. and Richard, A. H. (1994). Lippin Cotts Illustrated Review: Biochemistry $2^{\text {nd }}$ Ed. Lippin Cott. Williama and Wilkins. Philaldelphia. 213222

Robert, M. B. and Mathew, N. L. (2001). Cardiovascular Physiology, $8^{\text {th }}$ Ed. Mosby Inc. SK Louis. 156.

Stein G. M. and Berg, P. A. (1999) Characterization of immunological reactivity of patients with adverse effects during therapy with an aqueous mistletoe extract. Eur J. Med. Resp. 4:169-177.

Zheng, Z. J., Folson, A. R., Ma, J. Arnett, O. K. McGovean, P. G.; Eckfieldet, J. H. (1999). Plasma fatty acid composition and 6 years incidence of hypertension in middle-aged adult: the atherosclerasis risk in community (ARIC) study. Am. J. Epidemol. 150:492-500.

Received: $25 / 4 / 06$

Accepted: 22/11/06 